\title{
Prevalence of periprosthetic osteolysis after total hip replacement in patients with rheumatic diseases
}

This article was published in the following Dove Press journal:

Open Access Rheumatology: Research and Reviews

2 June 2012

Number of times this article has been viewed

\section{Rodolfo Perez Alamino \\ Carolina Casellini \\ Andrea Baňos \\ Emilce Edith Schneeberger \\ Susana Alicia Gagliardi \\ José Antonio Maldonado \\ Cocco \\ Gustavo Citera}

Section of Rheumatology, Instituto de Rehabilitación Psicofísica, Buenos Aires, Argentina
Correspondence: Gustavo Citera Chief Section of Rheumatology, Instituto de Rehabilitación Psicofísica,

Echeverría 955 (zip code 1428),

Buenos Aires, Argentina

Tel +54 | | 4788884 |

Fax +54 || 47885552

Email gustavocitera@gmail.com
Abstract: Periprosthetic osteolysis (PO) is a frequent complication in patients with joint implants. There are no data regarding the prevalence of PO in patients with rheumatoid arthritis (RA), juvenile chronic arthritis (JCA), ankylosing spondylitis (AS), and osteoarthritis (OA).

Objectives: To evaluate the prevalence of PO in patients with RA, JCA, AS, and OA, who have undergone total hip replacement (THR), and to identify factors associated with its development.

Methods: The study included patients diagnosed with RA (ACR 1987), AS (modified New York criteria), JCA (European 1977 criteria), and osteoarthritis (OA) (ACR 1990 criteria) with unilateral or bilateral THR. Demographic, clinical, and therapeutic data were collected. Panoramic pelvic plain radiographs were performed, to determine the presence of PO at acetabular and femoral levels. Images were read by two independent observers.

Results: One hundred twenty-two hip prostheses were analyzed (74 cemented, 30 cementless, and 18 hybrids). The average time from prosthesis implantation to pelvic radiograph was comparable among groups. PO was observed in 72 hips (59\%). In 55\% of cases, PO was detected on the femoral component, with a lower prevalence in RA (53\%) vs AS (64.7\%) and JCA (76.5\%). Acetabular PO was more frequent in JCA patients (58.8\%), compared with RA (11.6\%) and OA (28.5\%) patients ( $P=0.0001$ and $P=0.06$, respectively). There was no significant association between the presence of PO and clinical, functional, or therapeutic features.

Conclusion: The prevalence of PO was 59\%, being more frequent at the femoral level. Larger studies must be carried out to determine the clinical significance of radiologic PO.

Keywords: periprosthetic osteolysis, hip prosthesis, rheumatoid arthritis, juvenile chronic arthritis, ankylosing spondylitis

\section{Introduction}

In some patients, joint damage produced by different rheumatic diseases requires joint replacement in order to relieve pain and restore mobility and function. Periprosthetic osteolysis (PO) is a complication frequently observed in patients with joint implants. About $20 \%$ to $30 \%$ of patients will present evidence of osteolysis within ten years from the implant collocation. ${ }^{1-3} \mathrm{PO}$ is defined as lytic areas or bone loss in zones near the prosthesis detected by a conventional radiography. Patients with PO will frequently need a revision arthroplasty, increasing direct costs of patients care. On the other hand, it is common to delay the indication of total hip replacement (THR) in young patients for long periods of time due to fear of developing this complication, since they would eventually need two or three surgical revisions during their life. ${ }^{4-10}$ 
There are two types of aseptic PO:

a. that due to mechanical factors related to design and prosthesis characteristics and;

b. that caused by immunologic mechanisms capable of producing a graft-versus-host reaction generated by prosthetic material. It has been postulated that molecules released by such implants trigger a complex inflammatory response, releasing different pro-inflammatory cytokines, which induce osteoclast activation and subsequent periprosthetic bone resorption. ${ }^{9-21}$

Previous studies on PO have been performed almost exclusively on patients with $\mathrm{OA}^{3-7}$ So far, there is no data about the incidence and/or prevalence of PO in THR patients with chronic inflammatory diseases, such as RA, JCA, and AS.

The objective of this study was to evaluate the prevalence of PO in patients with RA, JCA, AS, and OA, who have undergone THR, to compare the frequency among groups and to identify possible factors associated to its development.

\section{Material and methods}

The study included patients diagnosed with RA (ACR 1987 criteria), JCA (European 1977 criteria), AS (modified New York criteria), and OA (ACR 1990 criteria), who have undergone unilateral or bilateral THR, with a time from prosthesis implantation greater than or equal to one year. ${ }^{22-24}$ Demographic, clinical, and therapeutic data of all patients were collected, as well as body mass index (BMI) and the presence of comorbid diseases.

Tender and swollen joint count, visual analog scale (VAS) for pain, VAS for activity, physician's global assessment, morning stiffness in minutes, and functional capacity (HAQ) were determined in patients with RA and JCA.

Lumbar pain at night, morning stiffness, VAS for pain and activity, physician's global assessment, lumbar spine mobility (modified Schober), functional capacity measured by Bath Ankylosing Spondylitis Functional Index (BASFI), and disease activity measured by Bath Ankylosing Spondylitis Disease Activity Index (BASDAI) were accessed in patients with AS.

VAS for pain and functional capacity evaluation by Western Ontario and McMaster Universities Arthritis Index WOMAC questionnaire were determined in OA patients.

Patients' medical records were revised to determine the treatments received. Duration of treatment with each diseasemodifying antirheumatic drug (DMARD) and cumulative doses of methotrexate and steroids were calculated.
Type of prosthesis (cemented, cementless, or hybrid), post-operatory complications, and frequency and cause of prosthesis revision, if any, were also recorded.

For evaluation of post-operatory results at the time of study, we calculated scales of pain, muscular strength, gait, and functional capacity of each operated hip on every patient, according to Merle d' Aubigné and Postel criteria modified by Salvati and Wilson. ${ }^{21}$ Each item was measured on a scale from one to ten, and a value of five or more was considered a good post-operative result.

Patients with THR due to traumatic or non-traumatic fracture and patients with prosthesis revision due to infectious osteolysis were excluded from this study.

Panoramic pelvic plain radiography was performed on each patient, taking into account the following requirements: anteroposterior view with focus on the pubic area, and X-rays including both hips up to the distal part of the femoral shafts. Since most of our patients have annual or biannual control radiographs, we reviewed those radiographs in order to obtain greater certainty on PO diagnosis.

Acetabular osteolysis was defined as the appearance of a radiolucid zone in the pelvic area around the acetabulum and femoral osteolysis was defined as the appearance of the same lesions in the femoral shaft area. The margins of each one of these lesions had to be sufficiently clear as to be delineated with a pencil.

In order to determine the location of each one of the osteolytic injuries, the femoral component was divided into seven zones (Gruen zones) ${ }^{22}$ and the acetabular component was divided into three zones (De Lee and Charnley zones) ${ }^{23}$ (Figure 1). All radiographs were evaluated by two independent observers, who were not aware of the clinical features of the patients. There were acceptable intra- and inter-observer correlations (kappa $=0.74$ and 0.47 , respectively).

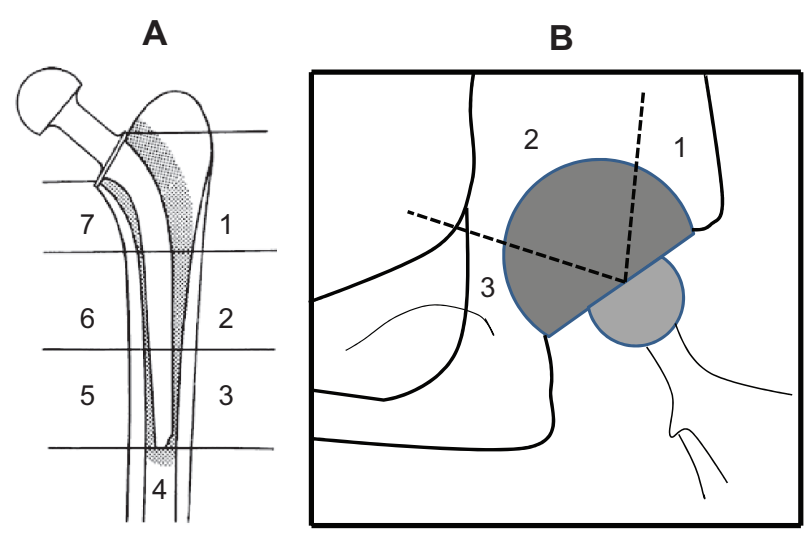

Figure I Radiologic osteolysis location according to: (A) Gruen zones and (B) De Lee and Charnley zones. 


\section{Statistical analysis}

Continuous variables were expressed as medians ( $\underline{\mathrm{m}})$ with their corresponding interquartile range (IQR) or as means (X) and \pm standard deviations (SD). Differences in frequency of PO among groups were compared by Chi-square or Fisher's exact test. Continuous variables were compared by Student's $t$-test with Levene's test for homogeneity of variance, analysis of variance (ANOVA), and/or Kruskal-Wallis's test. The possible association of the different factors related to the disease (in each group) and the development of PO were analyzed by a multiple logistic regression model, using presence or not of PO as a dependent variable. Intra- and inter-observer correlations were analyzed using kappa test. A value of $P<0.05$ was considered significant. SPSS software was used for statistical analysis.

\section{Results}

The study included 81 patients (39 RA patients, 11 JCA patients, 9 AS patients, and $22 \mathrm{OA}$ patients), who received 122 hip prostheses. Clinical and demographic features of patients are listed in Table 1.

For better understanding, number and type of prosthesis and time since implant collocation are depicted in Figure 2.

On the whole, we observed radiologic osteolysis in 72 out of the 122 evaluated hips (59\%). Median time since implant collocation was, for RA patients, 78 months (IQR 18-324) for right replacement, and 52 months (IQR 12-204) for left replacement. In AS patients, it was of 144 months (IQR 19-314) for right replacement and 103 months (IQR 19-300) for left replacement. In JCA patients, it was of 96 months
(IQR 48-174) for right replacement and 117 months (IQR 58-216) for left replacement. In OA patients, it was of 130.5 months (IQR 12-336) for right replacement and 51 months (IQR 12-320) for left replacement. There were no statistically significant differences among the different groups $(P=0.086)$.

Frequencies of radiologic $\mathrm{PO}$ in the different diseases and types of prostheses are detailed in Tables 2 and 3.

We observed that in 55\% of cases, radiologic osteolysis was detected on the femur. When femur component was divided into seven zones (Gruen zones), ${ }^{2}$ Gruen zones six and seven were the more frequently affected Figure 3.

The prevalence of pelvic osteolysis was $41.6 \%$, and it was more frequently observed in JCA patients (58.8\%), compared with RA (11.6\%) and OA (28.5\%) patients $(P=0.0001$ and $P=0.06$, respectively).

Of the 72 hips with osteolysis, only seven $(9.72 \%)$ had to be subjected to revision surgery as a consequence of clinical manifestations.

We did not observe any association between the presence of PO and demographic, clinical, functional, or therapeutic variables in the different diseases analyzed.

Patients with radiologic osteolysis presented scales of pain, muscular strength, gait, and functional capacity of each hip similar to that of patients without osteolysis (Table 4).

\section{Discussion}

Joint replacement is considered to be one of the orthopedic surgical procedures having the greatest impact in functional capacity and quality of life in rheumatic patients. Nevertheless, its success is often limited by implant

Table I Clinical and demographic features of patients with rheumatoid arthritis, juvenile chronic arthritis, ankylosing spondylitis and osteoarthritis

\begin{tabular}{|c|c|c|c|c|}
\hline & $\begin{array}{l}\text { Rheumatoid arthritis } \\
\mathbf{N}=39\end{array}$ & $\begin{array}{l}\text { Juvenile chronic arthritis } \\
\mathbf{N}=\text { II }\end{array}$ & $\begin{array}{l}\text { Ankylosing spondylitis } \\
\mathrm{N}=9\end{array}$ & $\begin{array}{l}\text { Osteoarthritis } \\
N=22\end{array}$ \\
\hline Age & 57 & 34 & 48 & 72.5 \\
\hline m (IQR) & $(50-64)$ & $(25-40)$ & $(42-53.5)$ & $(66-78)$ \\
\hline Gender: female & 26 & 8 & i & 14 \\
\hline (\%) & $(67)$ & (73) & (II) & $(64)$ \\
\hline Body mass index & 26.4 & 23.4 & 25.5 & 28.5 \\
\hline m (IQR) & $(24-3 \mid)$ & $(19.5-26)$ & $(22.5-28)$ & $(24-33)$ \\
\hline Disease duration (years) & 18 & 27 & 30 & 15 \\
\hline $\mathrm{m}(\mathrm{IQR})$ & $(13-25.5)$ & $(17-35)$ & $(14-36)$ & $(7-25)$ \\
\hline \multicolumn{5}{|l|}{ Functional class (\%) } \\
\hline I & $4(10)$ & 0 & I (II) & $8(36)$ \\
\hline II & $15(38.5)$ & $3(27)$ & $4(44)$ & $5(23)$ \\
\hline III & $15(38.5)$ & $8(73)$ & $4(44)$ & $8(36)$ \\
\hline IV & $5(13)$ & 0 & 0 & I (4.5) \\
\hline
\end{tabular}

Abbreviations: $\mathrm{m}$, median; IQR, interquartile range. 


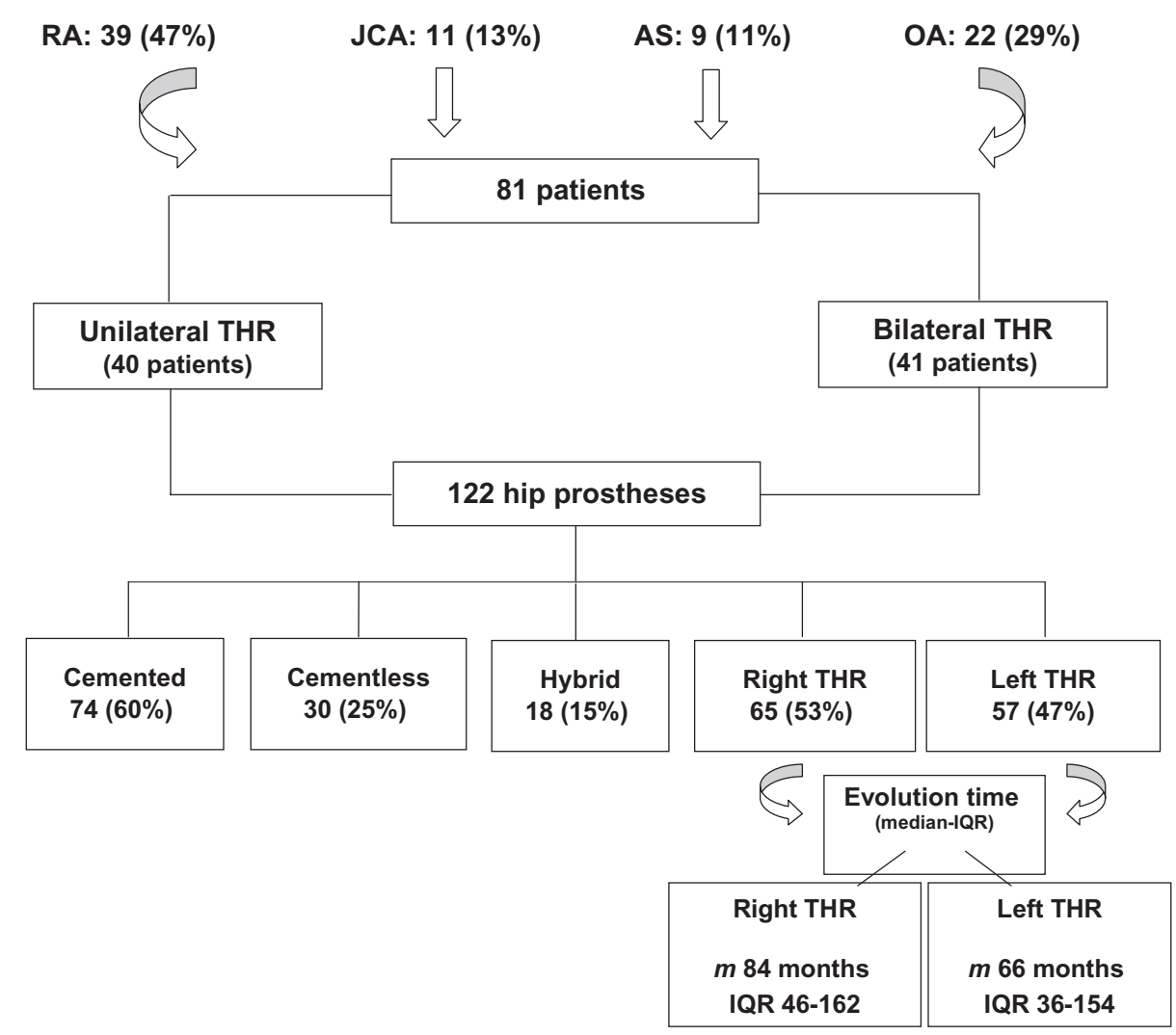

Figure 2 Features of total hip replacement.

Abbreviations: $m$, median; IQR, interquartile range.

loosening, which is very likely to occur over the course of time. This condition requires, on average, five to ten years for its development, and it is primarily caused by chronic osteoclastic bone resorption around the prosthetic surface.

In recent years, a great number of publications have tried to find an explanation for this process. The most accepted theory explains this phenomenon as an inflammatory response directed to particles released by the joint surface. This would produce a graft-versus-host reaction, followed by post-inflammatory cytokine activation that would end

Table 2 Prevalence of radiologic osteolysis in patients with RA, JCA, AS, and OA

\begin{tabular}{ll}
\hline Disease & $\begin{array}{l}\text { Periprosthetic osteolysis } \\
\text { No of hips }\end{array}$ \\
\hline Rheumatoid arthritis & 32 \\
(60 hips) & $(53 \%)$ \\
Juvenile chronic arthritis & 13 \\
(17 hips) & $(76.5 \%)$ \\
Ankylosing spondylitis & 11 \\
(17 hips) & $(64.7 \%)$ \\
Osteoarthritis & 16 \\
(28 hips) & $(57.1 \%)$ \\
\hline
\end{tabular}

with osteoclast activation and a subsequent periprosthetic bone resorption. ${ }^{9-20}$

However, an individual susceptibility to develop PO may exist, since its frequency may vary in patients with the same pathology and similar joint implants. ${ }^{10}$

Previous studies have assessed the prevalence of this process in patients with hip osteoarthritis; however, to our knowledge, there are few studies that evaluate the prevalence of PO in patients with chronic inflammatory rheumatic diseases (RA, JCA, and AS) that receive THR. Recently, Zwartele et al performed a literature review on cementless THA in patients with RA. They found only 37 studies that matched

Table 3 Prevalence of radiologic osteolysis according to type of prosthesis

\begin{tabular}{ll}
\hline Type of prosthesis & $\begin{array}{l}\text { Periprosthetic osteolysis } \\
\text { No of hips (\%) }\end{array}$ \\
\hline Cemented & $50 *$ \\
(74 hips) & $(67.6 \%)$ \\
Cementless & 13 \\
(30 hips) & $(43.3 \%)$ \\
Hybrid & 9 \\
(18 hips) & $(50 \%)$ \\
\hline
\end{tabular}




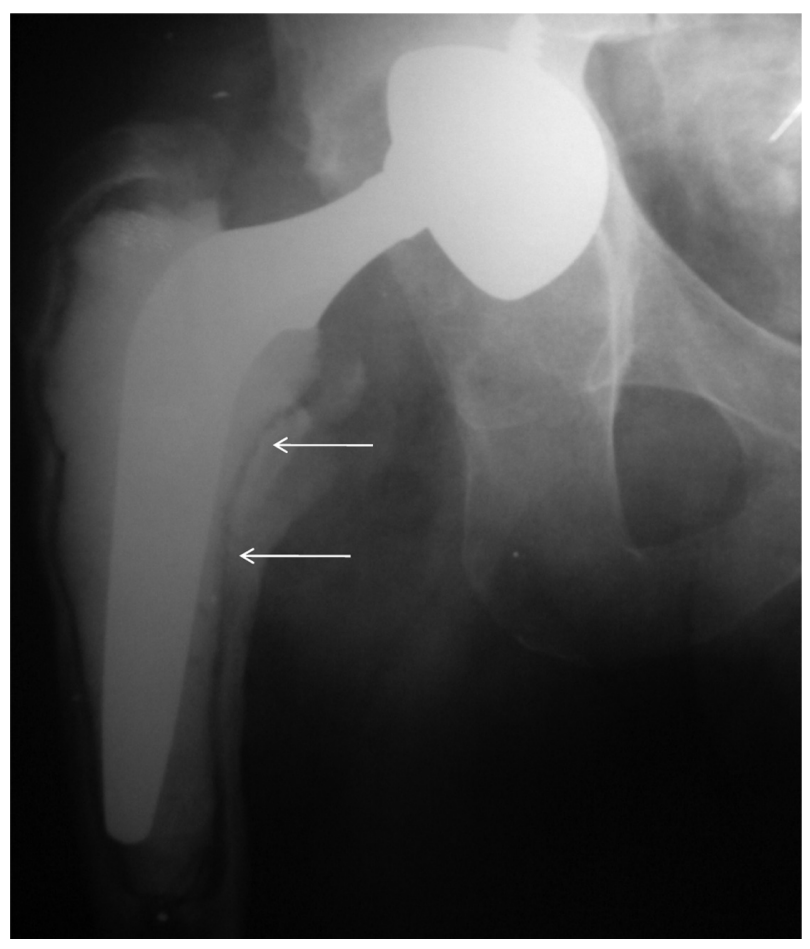

Figure 3 Radiologic osteolysis in Gruen zones 6 and 7 (white arrows).

the search criteria. Failure rates of aseptic loosening were reported in six out of 26 studies of the cup and in two out of 25 studies of the stem. ${ }^{25}$

In our group, the prevalence of PO was 59\%, being more frequent at the femoral level ( $55 \%$ of cases), and in cemented prostheses. We also observed a higher frequency of PO in patients with JCA, although without statistical significance.

It is important to point out that a very low percentage of patients $(9.72 \%)$ whose prostheses presented radiologic

Table 4 Association between periprosthetic osteolysis and functional assessment of total hip replacement (according to the Merle d' Aubigné and Postel score modified by Salvati and Wilson)

\begin{tabular}{|c|c|c|}
\hline \multirow{3}{*}{$\begin{array}{l}\text { Functional assessment } \\
\text { of prosthesis }\end{array}$} & \multicolumn{2}{|c|}{ Periprosthetic osteolysis } \\
\hline & Yes & No \\
\hline & Mean \pm (SD) & Mean $\pm(S D)$ \\
\hline \multicolumn{3}{|l|}{ Right prostheses } \\
\hline - Pain & $8.6 \pm 1.5$ & $8.3 \pm 2.3$ \\
\hline - Muscular strength & $6.7 \pm 1.4$ & $7.2 \pm 1.9$ \\
\hline - Gait & $6.7 \pm 2.7$ & $6.6 \pm 3$ \\
\hline - Functional capacity & $5.9 \pm 3$ & $6.4 \pm 3.2$ \\
\hline \multicolumn{3}{|l|}{ Left prostheses } \\
\hline - Pain & $9 \pm 1.6$ & $8.5 \pm 1.7$ \\
\hline - Muscular strength & $6.8 \pm 1.6$ & $7.1 \pm 1.9$ \\
\hline - Gait & $6.6 \pm 2.8$ & $6.6 \pm 3.1$ \\
\hline - Functional capacity & $6.6 \pm 3$ & $6.4 \pm 3$ \\
\hline
\end{tabular}

Abbreviation: SD, Standard deviation. osteolysis required revision surgery. Furthermore, when evaluating the functional impact that this complication may generate on patients, we observed that those with radiologic osteolysis presented scales of pain, muscular strength, gait, and functional capacity similar to that of patients without osteolysis.

Although our patients were not assessed lengthwise following prosthesis implantation, we did not find a clear significant association between the presence of radiologic osteolysis and clinical and therapeutic features.

Looking at our findings, we consider that more studies should be performed in order to evaluate the real clinical significance of PO in patients with chronic inflammatory rheumatic pathologies. A better understanding of this complication will allow the conducting of preventive and therapeutic strategies in the near future.

\section{Disclosures}

The study was supported in part by Fundación Reumatológica Argentina, Dr Osvaldo García Morteo. Fundación Reumatológica Argentina, did not play a role in the investigation.

\section{References}

1. Fender D, Harper W, Gregg PJ. Outcome of Charnley total hip replacement across a single region in England: the results at five years from a regional hip register. J Bone Joint Surg Br. 1999;81:577-581.

2. Callaghan JJ, et al. Charnley total hip arthroplasty in patients less than fifty years old. A twenty to twenty five years follow up note. $J$ Bone Joint Surg Am. 1998;80:704-714.

3. Kim YH, Kim JS, Cho SH. Primary total hip arthroplasty with a cementless porous-coated anatomic total hip prosthesis: 10 to 12 years results of prospective and consecutive series. J Arthroplasty. 1999; 14:538-548.

4. Benkenbaugh RD, et al. Total hip arthroplasty: A review of three hundred thirty-three cases with long follow up. J Bone Joint Surg. 1978;60-A:206-213.

5. Collis DK. Long-term (twelve to eighteen years) follow up of cemented total hip replacement in patients who were less than fifty years old: A follow up note. J Bone Joint Surg. 1991;73-A:593-597.

6. Bourne RB, Rorabeck CH, Ghazal ME, Lee MH. Pain in the thigh following total hip replacement with a porous-coated anatomic total hip prosthesis for osteoarthrosis. J Bone Joint Surg. 1994;76-A: 1464-1470.

7. Bugbee JW, et al. Long-term consequences of stress shielding in cementless total hip arthroplasty: J Bone Joint Surg. 1997;79-A:1007-1012.

8. Callaghan JJ. Results of primary total hip arthroplasty in young patients. Instr Course Lect. Am Acad Orthop Surg. 1994;43:315-321.

9. Campbell ACL, Rorabeck CH, Bourn RB, Chess D, Nott L. Thigh pain after cementless hip arthroplasty: Annoyance or ill omen. J Bone Joint Surg. 1992;74-B:63-66.

10. Gallo J, et al. Bone remodeling, particle disease and individual susceptibility to Periprosthetic osteolysis. Physiol Res. 2008;57: 339-349.

11. Goodman S. Wear particulate and osteolysis. Orthop Clin North Am. 2005;36:41-48.

12. Schwarz EM, Looney RJ, O'Keefe RJ. Anti TNF-alpha as a clinical intervention for periprosthetic osteolysis. Arthritis Res. 2000;2: $165-168$. 
13. Looney RJ, Schwarz E, Boyd A, et al. Periprosthetic osteolysis: an immunologist's update. Curr Opin Rheumatol. 2006;18:80-87.

14. Abu-Amer Y, Darwech I, et al. Aseptic loosening of total joint replacements: mechanisms underlying osteolysis and potential therapies. Arthritis Res Ther. 2007;9 Suppl 1:S6:1-7.

15. Mandelin J, Li TF, Hukkanen M, et al. Interface tissue fibroblasts from loose total hip replacement prosthesis produce receptor activator of nuclear factor-kappa B ligand, osteoprotegerin, and cathepsin K. J Rheumatol. 2005;32:713-720.

16. Harris WH. The problem is osteolysis. Clin Orthop Relat Res. 1995;311:46-53.

17. Jacobs JJ, Sumner DR, Galante JO. Mechanisms of bone loss associated with total hip replacement. Orthop Clin North Am. 1993;75:802-813.

18. Itonaga I, Sabokbar A, Murray DW, et al. Effect of osteoprotegerin and osteoprotegerin ligand on osteoclast formation by arthroplasty membrane derived macrophages. Ann Rheum Dis. 2000;59:26-31.

19. Wilkinson JM, Hamer AJ, Stockley I, Eastell R. Polyethylene wear rate and osteolysis: critical threshold versus continuous dose-response relationship. J Orthop Res. 2005;23:520-525.

20. Schwarz EM, O'Keefe RJ, Xing L, et al. RANKL and OPG: Where are we now and what about future treatment use? Curr Opin Orthop. 2005;16:370-375.
21. Merle d'Aubigne R, Postel M. Functional results of hip arthroplasty with acrylic prosthesis. J Bone Joint Surg. 1954;36-A:451-475.

22. Arnett FC, Edworthy SM, Bloch DA, et al. The American Rheumatism Association 1987 revised criteria for the classification of rheumatoid arthritis. Arthritis Rheum. 1988; 31:315-324.

23. European League Against Rheumatism (EULAR). Newsletter 4: Nomenclature and Classification of Arthritis in Children. Basel. National. Zeitung AG: 1977. (AS-modified New York criteria): Van der Linden S, Valkenburg HA, Cats A. Evaluation of diagnostic criteria for ankylosing spondylitis: a proposal for modification of the New York criteria. Arthritis Rheum. 1984;27:361-368.

24. Altman R, Alarcon G, Appelrouth D, et al. The American College of Rheumatology criteria for the classification and reporting of osteoarthritis of the hip. Arthritis Rheum. 1991;34:505-514.

25. Gruen TA, McNeice GM, Amstutz HC. "Modes of failure" of cemented stem-type femoral components: A radiographic analysis of loosening. Clin Orthop. 1979;141:17-27.

26. DeLee JG, Charnley J. Radiological demarcation of cemented sockets in total hip replacement. Clin Orthop. 1976;121:20-32.

27. Zwartele RE, Witjes S, Corneli Doets H, Stijnen T, Poll RG. Cementless total hip arthroplasty in rheumatoid arthritis: a systematic review of the literature. Arch Orthop Trauma Surg. 2012;132:535-546.
Open Access Rheumatology Research and Reviews

\section{Publish your work in this journal}

Open Access Rheumatology Research and Reviews is an international, peer-reviewed, open access journal, publishing all aspects of clinical and experimental rheumatology in the clinic and laboratory including the following topics: Pathology, pathophysiology of rheumatological diseases; Investigation, treatment and management of rheumatological

\section{Dovepress}

diseases; Clinical trials and novel pharmacological approaches for the treatment of rheumatological disorders. The manuscript management system is completely online and includes a very quick and fair peerreview system, which is all easy to use. Visit http://www.dovepress.com/ testimonials.php to read real quotes from published authors. 